\title{
Simulating attenuation in saturated sandstones with Dvorkin-Mavko model
}

\author{
Simonária Fidelis ${ }^{1}$, Marco Ceia ${ }^{1}$, Roseane Misságia ${ }^{1}$, Entities ${ }^{1}$ - UENF/LENEP
}

Copyright 2021, SBGf - Sociedade Brasileira de Geofísica

This paper was prepared for presentation during the $17^{\text {th }}$ International Congress of the Brazilian Geophysical Society held in Rio de Janeiro, Brazil, 16-19 August 2021.

Contents of this paper were reviewed by the Technical Committee of the $17^{\text {th }}$ International Congress of the Brazilian Geophysical Society and do not necessarily represent any position of the SBGf, its officers or members. Electronic reproduction or storage of any part of this paper for commercial purposes without the written consent of the Brazilian Geophysical Society is prohibited.

\section{Abstract}

Seismic methods are often used for reservoir characterization aiding structural delineation as well as rock property inference. Seismic attenuation is sensible to porosity, fluid saturation and permeability, such way the monitoring of that property can be very useful for understanding the differences of rock properties and fluid distribution along the reservoir. Inverse quality factor is direct related to seismic attenuation and can be estimated using several theoretical models. In this work, we used the Dvorkin-Mavko model for simulating $P$ and $S$ inverse quality factors (Q) of brine saturated sandstones and compare to experimental results. The results showed a relationship between inverse $Q$ and porosity exhibiting a linear trend similar to what was observed in the experimental estimates.

\section{Introduction}

Seismic attenuation is one of the rock properties intensively studied for reservoir characterization. This property brings the link between elastic velocities, pore space and transport properties. Early works like Biot (1956) addressed such relationship and provided the first attenuation models. Subsequently works as Mavko and Jizba (1991) and Dvorkin et al. (1994) showed that not only the global flow affects the seismic wave attenuation, but local (squirt) flow issues are also important especially at high-frequencies. Dvorkin and Mavko (2006) introduced a model for estimating both $\mathrm{P}$ - and $\mathrm{S}$ - wave quality factors $\left(Q_{p}^{-1}\right.$ and $Q_{s}^{-1}$ respectively) in rocks exhibiting partial or full saturation. This model was applied for estimating the inverse quality factor of sandstone rocks and compare to measurement estimates obtained at ultrasonic frequencies.

\section{Methodology}

The Dvorkin - Mavko model was used to simulate the quality factor of the $P$ wave in brine saturated sandstones. To obtain all the necessary properties when using the Dvorkin - Mavko model, the Gassmann, Biot, and Geertsma-Smit models were also used. Next, all the models used will be detailed.

\section{Theoretical models}

\section{Gassmann model}

Gassmann's (1951) model correlates petrophysical properties of dry rock and the fluid contained within it with the incompressibility of saturated rock.

In addition, based on the premise that the saturating fluid has low viscosity, it considers that the saturation of the rock will not alter the modulus of rock shear. Mathematically, it is defined as:

$$
" \frac{K_{\text {sat }}}{K_{\text {min }}-K_{\text {sat }}}=\frac{K_{d r y}}{K_{\text {min }}-K_{d r y}}+\frac{K_{f l}}{\emptyset\left(K_{\min }-K_{f l}\right)} ; G_{\text {sat }} \text { (1) }
$$

Where, $K_{\text {sat }}, K_{\text {min }}, K_{d r y}$ and $K_{f l}$ are compression module of saturated rock, mineral matrix, dry rock, and saturating fluid, $\varnothing$ are the porosity and $G_{d r y}$ and $G_{\text {sat }}$ shear modulus of dry and saturated rock.

Equation 1 calculates the Gassmann theoretical compressibility module of the rock saturated by a fluid. With these values of the saturated rock and the new average rock density it is possible, to calculate the wave propagation velocities $\mathrm{P}$ and $\mathrm{S}$ for the saturated rock:

$$
\begin{gathered}
" V_{\text {psat }}=\sqrt{\frac{K_{\text {sat }}+\left(\frac{4}{3}\right) G_{\text {sat }}}{\rho_{\text {sat }}}}, " \\
" V_{\text {ssat }}=\sqrt{\frac{G_{\text {sat }}}{\rho_{\text {sat }}}}, " \\
" \rho_{\text {sat }}=\rho_{\text {dry }}+\emptyset \rho_{f l} .
\end{gathered}
$$

Where the $V_{\text {psat }}$ and $V_{\text {ssat }}$ are the $\mathrm{P}$ and $\mathrm{S}$ wave velocity to saturated rock, $\rho_{\text {sat }}$ is the bulk density of the saturated rock, $\rho_{d r y}$ is the dry density, and $\rho_{f l}$ is the fluid density.

\section{Biot's velocity relations}

Biot (1956) derived theoretical formulas for predicting the frequency-dependent velocities of saturated rocks in terms of the dry-rock properties. That formulation incorporates some, but not all, of the mechanisms of 
viscous and inertial interaction between the pore fluid and the mineral matrix of the rock (Mavko et al., 2009).

An important observation to be made is that, like the Gassmann model, the Biot model also considers that the change in the fluid contained within the pores of the rock does not change the shear modulus of the rock. Thus, the shear modulus for dry rock is equivalent to the shear modulus of saturated rock (Makarynska et al., 2010).

The calculation of velocities for Biot's high frequencies (infinite frequencies) is done using the equations below (Mavko et al., 2009):

$$
\begin{aligned}
& =\left\{\frac { 1 } { \rho _ { 0 } ( 1 - \emptyset ) + \emptyset \rho _ { f l } ( 1 - \gamma ^ { - 1 } } \left[\left(K_{f r}+\frac{4}{3} G_{f r}\right)\right.\right. \\
& \left.\left.+\frac{\emptyset \frac{\rho}{\rho_{f l}} \gamma^{-1}+\left(1-\frac{K_{f r}}{K_{0}}\right)\left(1-\frac{K_{f r}}{K_{0}}-2 \emptyset \gamma^{-1}\right)}{\left(1-\frac{K_{f r}}{K_{0}}-\emptyset\right) \frac{1}{K_{0}}+\frac{\emptyset}{K_{f l}}}\right]\right\}, ",
\end{aligned}
$$

$$
" v_{s \infty}=\left(\frac{K_{f r}}{\rho-\emptyset \rho_{f l} \gamma^{-1}}\right)^{1 / 2}, "
$$

$$
" \rho=\rho_{0}(1-\emptyset)+\rho_{f l} \emptyset . "
$$

Where $K_{f r}, G_{f r}$, are the effective bulk and shear moduli of the rock frame, $K_{0}$ is the bulk modulus of the mineral material making up the rock, $K_{f l}$ is the effective bulk modulus of the pore fluid, $\varnothing$ is the porosity, $\rho_{0}$ is the mineral density, $\rho_{f l}$ is the fluid density, $\gamma$ is the tortuosity parameter.

\section{Geertsma-Smit approximations of Biot's relations}

Biot's theoretical formulas predict the frequencydependent velocities of saturated rocks in terms of the dry-rock properties. Low and middle-frequency approximations (Geertsma and Smit, 1961) of his relations may be expressed as:

$$
" V_{p}^{2}=\frac{V_{p \infty}^{4}+V_{p 0}^{4}\left(\frac{f_{c}}{f}\right)^{2}}{V_{p \infty}^{2}+V_{p 0}^{4}\left(\frac{f_{c}}{f}\right)^{2}} .
$$

Where $V_{p}$ is the frequency-dependent $\mathrm{P}$-wave velocity of saturated rock $V_{p o}$ is the Biot-Gassmann low-frequency limiting P-wave velocity, $V_{p \infty}$ is the Biot high-frequency limiting P-wave velocity, $f$ is the frequency and $f_{c} \mathrm{~s}$ Biot's reference frequency, which determines the low-frequency range, $f \ll f_{c}$, and the high-frequency range, $f \gg f_{c}$, given by

$$
" f_{c}=\frac{\emptyset \eta}{2 \pi \rho_{f l} k} . "
$$

Where $\varnothing$ is porosity, $\rho_{f l}$ is the fluid density, $\eta$ is the viscosity of the pore fluid and $k$ is the absolute permeability of the rock.

\section{Dvorkin-Mavko attenuation model}

Dvorkin and Mavko (2006) present a theory for calculating the P- and S-wave inverse quality factors. The basis for the quality factor estimation is the standard linear solid model that links the inverse quality factor $Q^{-1}$ to the corresponding elastic modulus $M$ versus frequency $f$ dispersion as (Mavko et al., 2009):

$$
" Q^{-1}(f)=\frac{\left(M_{\infty}-M_{0}\right)\left(\frac{f}{f_{c}}\right)}{\sqrt{M_{0}} M_{\infty}\left[1+\left(\frac{f}{f_{c}}\right)^{2}\right]} .
$$

Where $M_{0}$ and $M_{\infty}$ are the low- and high-frequency limits of the modulus $M$ and $f_{c}$ is the critical frequency.

\section{Dataset}

The core samples used in this modeling were taken from He et al., (2010) (Figure 1 and Table 1). Are sandstone from the W formation of the WXS Depression and covered low to nearly high porosity and permeability ranges.

In this work, laboratory data taken from Fidelis (2017) were used in this work to test the modeled data. Sandstones came from Utah, Ohio and Tennessee formation. Table 2 refers to the porosity and $\mathrm{Qp}$ of sandstones saturated with brine (1.3455 ppm of $\mathrm{NaCl}$ ). The frequency range used by Fidelis (2017) was $1.3 \mathrm{MHz}$. 


\begin{tabular}{|c|c|c|c|c|}
\hline Core & ${ }^{*} \mathrm{~W}-7$ & W-10 & W-11 & W-13 \\
\hline Well & $1212 B$ & 1214 & 1214 & $114 \mathrm{~N} 2$ \\
\hline Depth (m) & 2347.17 & 2478.35 & 2658.33 & 1868.6 \\
\hline$P_{\text {diff }}(\mathrm{MPa})$ & 28.7 & 30.7 & 33.5 & 21.6 \\
\hline Quartz (\%) & $\sim 87$ & $\sim 80$ & $\sim 85$ & $\sim 75$ \\
\hline Feldspar (\%) & $\sim 5$ & $\sim 15$ & $\sim 10$ & $\sim 10$ \\
\hline Clay (\%) & $<5$ & $\sim 1$ & $<5$ & $<15$ \\
\hline Calcite (\%) & $\sim 1.5$ & $<4$ & $<0.1$ & $<0.1$ \\
\hline Dolomite (\%) & $\sim 1.5$ & 0 & 0 & 0 \\
\hline$\rho_{f}\left(\mathrm{~g} / \mathrm{cm}^{3}\right)$ & 2.6497 & 2.6487 & 2.6445 & 2.6375 \\
\hline$K_{\mathrm{s}}(\mathrm{GPa})$ & 37.608 & 41.359 & 38.0036 & 35.8677 \\
\hline$G_{\mathrm{s}}(\mathrm{GPa})$ & 39.1073 & 39.7104 & 38.1724 & 31.5108 \\
\hline Grain size (mm) & $0.07-0.2$ & $0.1-0.25$ & $0.25-0.5$ & $0.25-1$ \\
\hline$D(\mathrm{~mm})$ & 25.72 & 25.64 & 25.7 & 25.48 \\
\hline$L(\mathrm{~mm})$ & 40.3 & 49.82 & 41.21 & 45.94 \\
\hline$\phi(\%)$ & 16.46 & 13.55 & 17.87 & 23.73 \\
\hline$k(\mathrm{mD})$ & 3.872 & 2.495 & 63.552 & 424.2 \\
\hline$\rho_{d y}\left(\mathrm{~g} / \mathrm{cm}^{3}\right)$ & 2.13 & 2.24 & 2.05 & 1.86 \\
\hline$V \mathrm{p}_{d y}(\mathrm{~m} / \mathrm{s})$ & 3699.0 & 3875.0 & 3833.0 & 3388.0 \\
\hline$V \mathrm{~s}_{\phi y}(\mathrm{~m} / \mathrm{s})$ & 2362.5 & 2563.5 & 2503.0 & 2177.5 \\
\hline$\gamma$ & 0.0055 & 0.0037 & 0.0057 & 0.0116 \\
\hline
\end{tabular}

Figure 1 - Data used in modeling. $P_{\text {diff }}$ is the differential pressure between confining pressure and pore fluid pressure at core collection depth; $\rho_{f}, K_{f}$ and $G_{f}$ are the estimated density, the bulk and shear moduli of solid matrix based on the thin section under the optical microscope; $D$ is the diameter; $L$ is the length; is the effective porosity; $k$ is the permeability; $\rho_{d r y}$ is the dry density calculated after cleaning and oven-drying; $V_{p d r y}$ and $V_{\text {sdry }}$ are the measured compressional and shear velocities at dry conditions; and $\eta$ is the estimated microfracture aspect ratio (He et al., 2010).

Table 1- Fluid property (He et al., 2010).

\begin{tabular}{|c|c|}
\hline Fluid type & Brine (NaCl 26000ppm) \\
\hline Temperature (으) & 15 \\
\hline $\begin{array}{c}\text { Bulk moduli od the fluid } \\
\text { (GPa) }\end{array}$ & 2.27 \\
\hline Viscosity (Pa.s) & 0.00114 \\
\hline
\end{tabular}

Table 2 - Porosity and P wave quality factor (Qp) data taken from Fidelis (2017).

\begin{tabular}{|c|c|}
\hline Qp & Porosity (\%) \\
\hline 13.57 & 15.10 \\
\hline 11.97 & 15.76 \\
\hline 15.29 & 10.12 \\
\hline 16.21 & 10.25 \\
\hline 16.45 & 7.71 \\
\hline 16.73 & 7.92 \\
\hline
\end{tabular}

\section{Results}

As indicated in Equation 10, the quality factor varies with frequency, given that, for testing purposes, the quality factor was modeled for two random frequency bands, 0.7 $\mathrm{MHz}$ and $1.3 \mathrm{MHz}$. According to Biot's, the critical frequency was classified in the high-frequency range for the modeled data , $f \gg f_{c}$.

Figure 2 shows the quality factor of the $P$ wave, varying with porosity. As can be seen, the results for the frequency of $1.3 \mathrm{MHz}$ were higher than for the frequency of $0.7 \mathrm{MHz}$, and with the increase in porosity, the quality factor drops, according to the literature.

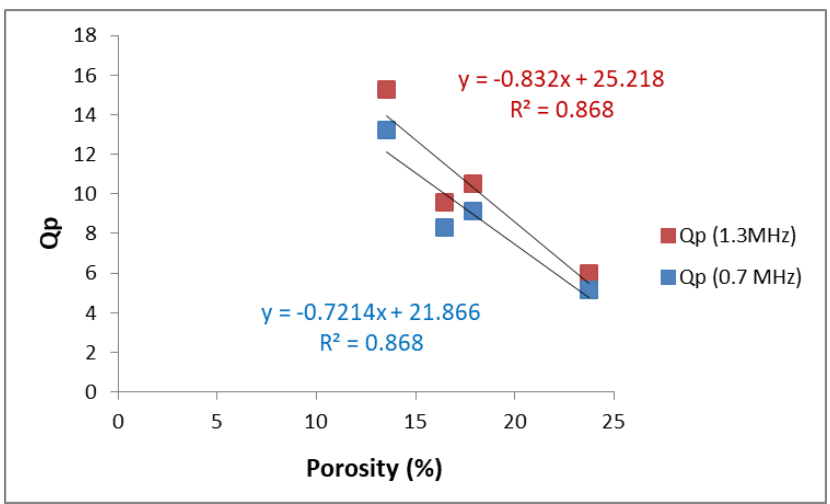

Figure 2- $\mathrm{P}$ wave quality factor versus porosity. Red squares refer to the frequency of $1.3 \mathrm{MHz}$ and blue squares refer to the frequency of $0.7 \mathrm{MHz}$.

To test the modeling of this work, a set of attenuation data analyzed in the laboratory from Fidelis (2017) was compared with the results of the modeling.

Only data of the same frequencies were used for comparison, that is, $1.3 \mathrm{MHz}$.

Figure 3 presents the results of the data modeled in this work and the data taken from Fidelis (2017). Employing this figure, it can be said that the theoretical models were able to estimate very well the attenuation in sandstones saturated with brine since the modeled data were in the same trend as the laboratory data.

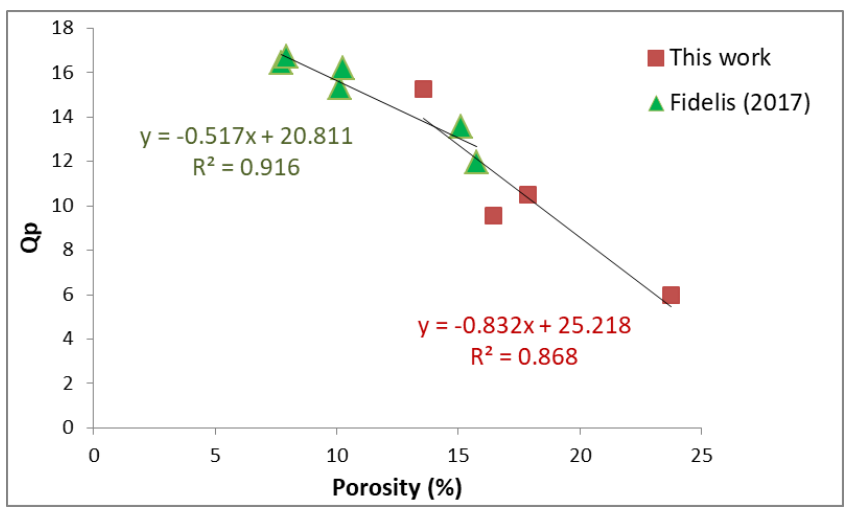


Figure 3- $\mathrm{P}$ wave quality factor versus porosity. Red squares refer to the modeling of this work and the green triangles given by Fidelis (2017). The correlation coefficients for the data in this work and the Fidelis (2017) data were respectively 0.868 and 0.916 .

\section{Conclusions}

The theoretical models used in this work were able to estimate the attenuation in sandstones saturated with brine effectively, in addition, they presented a linear tendency with porosity, showing a correlation coefficient of 0.868 .

When comparing the results of theoretical models with laboratory results, both exhibited the same trend, indicating that the model was accurate for predicting the inverse $\mathrm{Q}$ of the studied rocks.

\section{Acknowledgments}

This study was financed in part by the Coordenação de Aperfeiçoamento de Pessoal de Nível Superior - Brazil (CAPES) - Finance Code 001. MC and RM thank INCT/Geofisica for financial support; and also, CNPq for their Research Grants of Productivity in Technological Development and Innovation - DT II.

\section{References}

BIOT, M. A. Theory of propagation of elastic waves in a fluid-saturated porous solid. I. low-frequency range and II. higher frequency range. The Journal of the acoustical Society of america, ASA, V. 28, p. 168-191, 1956.

DVORKIN, J. P.; MAVKO, G. Modeling attenuation in reservoir and nonreservoir rock. The Leading Edge, Society of Exploration Geophysicists, V. 25, n. 2, p. 194197, 2006.

DVORKIN, J.; MAVKO, G.; NUR, A., Squirt flow in fully saturated rocks. Geophys. V. 60, p.97-107, 1995.

FIDELIS, S. S. Analysis of the relationship between permeability, porosity and elastic properties in dry and brine-saturated rocks (Dissertation) State University of Northern Fluminense, Macaé - RJ, 2017.

GASSMANN, F. Uber die elastizitat poroser medien. Verteljahrss-christ der Naturforschenden Gesellschaft in Zurich, V. 96, p. 1-2, 1951

GEERTSMA, J, SMIT, D.C. Some aspects of elastic wave propagation in fluid-saturated porous solids. Geophys., V. 26, p. 169-181, 1961.

HE, T.; ZOU, C.-C.; PEI, F.-G.; REN, K.-Y.; KONG, F.-D.; SHI, G. Laboratory study of fluid viscosity induced ultrasonic velocity dispersion in reservoir sandstones. Applied Geophysics, Springer, V. 7, p. 2, n.114-126, 2010.
MAVKO, G.; JIZBA, M. Estimating grain-scale fluid effects on velocity dispersion in rocks. Geophys., V. 56, p.19401949, 1991.

MAVKO, G.; MUKERJI, T.; DVORKIN, J. The rock physics handbook: Tools for seismic analysis of porous media. Cambridge University Press, 2009.

MAKARYNSKA, D; GUREVICH, B; BEHURA, J; BATZLE, $M$. Fluid substitution in rocks saturated with viscoelastic fluids. Geophysics, V. 75, p.115-122, 2010.

Available at: https://doi.org/10.1190/1.3360313 